WTO Public Forum, AIPPI's Working Session "New Digital Technologies: the protagonists of a change in perspective in the Global Supply Chain", Geneva, $8^{\text {th }}$ October 2019

\title{
Can Artificial Intelligence and the Internet of Things be Governed to Achieve the UN Sustainable Development Goals? An Intellectual Property Law Perspective
}

\author{
Guido Noto LA DIEGA, PHD FHEA
}

1. In this speech, I would like to discuss how Artificial Intelligence (AI) and the Internet of Things (IOT) can improve the global supply chain and facilitate the achievement of the UN sustainable development goals. In this context, I will critically assess whether intellectual property (IP) laws can play a positive role in governing these technologies and unleashing their 'sustainability-friendly' potential. I will offer a European IP perspective, with a focus on patent law, but many of the things I will say raise similar issues in other jurisdictions and in other IP sub-systems, such as copyright and trademarks.

2. The 2030 UN Agenda for Sustainable Development is our main hope to have peace and prosperity in a near future. At its heart are the 17 Sustainable Development Goals, such as no poverty, zero hunger, good health, decent work and economic growth, industry, innovation and infrastructure, and climate action. They are an urgent call for action, a call that we can no longer ignore.

3. The WTO is central to achieving the UN Sustainable Development Goals. The 2018 report "Mainstreaming trade to attain the Sustainable Development Goals" showed that by implementing pro-growth and pro-development trade reforms and by fostering stable and fair-trading relations, the WTO is playing an important role in delivering the UN Sustainability Goals.

4. The Mainstreaming trade report identified some steps which would help ensure that international trade contributes to accelerating progress in achieving the sustainable development goals. These steps include supporting micro, small and medium-sized enterprises (SMEs) to engage in international trade; enhancing the services sector; and ensuring that non-tariff measures do not become barriers to trade. The technologies that I will talk about today can play a crucial role in making sure that international trade can be a means to achieve the sustainable development goals. I am talking about $\mathrm{Al}$ and the loT.

5. Al is an umbrella term for autonomous and 'intelligent' technologies. One of the main distinctions in the field is between general Al and narrow Al. Whereas Artificial General Intelligence (AGI) may finally replace humans because, quoting Goertzel, it seeks to "engineer human-level general intelligence-based theoretical models", narrow AI "develops software to solve limited practical problems". Hence, narrow Al - that is the only type of Al we currently have - aims not to replace humans, but to improve their life, for instance in the fields of predictive analytics, driverless cars, care robots, speech recognition, and data mining.

6. A critical distinction in the field is between supervised and unsupervised learning. Most Al algorithms - such as the algorithm that decides what you see on your Facebook feed - are "supervised". This means that for the machine to learn, there must be a team of human beings that train the algorithm with labelled datasets. For example, there will be a team in a developing country that will tell Facebook that the picture of a cat represents indeed a cat. In unsupervised learning models, the Al learns through experience, without the need for labelled training data. Most forms of Al are narrow - they resolve well-defined problems - and supervised - they require some human intervention. The days of 2001 Space Odyssey's Hal are yet to come. 
7. So, what is the link between Al and sustainable development? Let us focus on the sustainability goal "good health and well-being". Al is increasingly used in healthcare for a number of reasons, including more accurate prediction of diseases, such as cancer. One need only think of a deep learning machine that scans 1,000,000 pictures of breasts and will be able to tell the doctors which breast are likely to develop cancer and which ones are not. This would be fantastic, but there would be some drawbacks. The main one would be that $\mathrm{Al}$ is a black box: we may predict that certain breasts are likely to develop cancer, but we would not know why. And what scientists, lawyers, and citizens care is not predicting that something will happen, what matters is why it will happen.

8. There is consensus that Al has unprecedented potential to realise the sustainability agenda and improve the global supply chain. The other key enabler is the loT, that refers to all those 'smart' devices that are connected to the Internet, equipped with sensors and actuating capabilities. Your smartphone, Amazon Echo, Apple Watch, Google's Nest Thermostat. The plane you have used to come here. The phrase was coined exactly 30 years ago by Procter \& Gamble's Kevin Ashton. He saw the loT as the fundamental disruptor of existing supply chains thanks to the fact that machines could communicate with each other without human intervention. We now have accurate real-time information about our products wherever they are, because it is the product itself that talks to us.

9. To provide just an example of how the loT is pivotal to sustainability and international trade let us simply focus on one aspect. In particular, the WTO considers enhancing the services sector as a key step to making sure that international trade contributes to achieving the sustainable development goals. Enhancing the services sector. No other technology will bring an as extraordinary revolution on this front as the loT. Our understanding of trade - and the relevant regulation - has always relied on a fundamental dichotomy between goods and services. For example, disputes regarding goods fall under the General Agreement on Tariffs and Trade and the Agreement on Technical Barriers to Trade. Conversely, if services are at issue, the General Agreement on Trade in Services governs the litigation. With the loT, traditional dichotomies become blurred. Indeed, smart devices are an inextricable mixture of goods, services, hardware, software, and data.

10. Servitisation has been a trend for many years now and, for a good reason, it is at the centre of many conversations we are having here at the WTO Public Forum. As research by Guillot found, 70\% manufacturers are adopting servitisation, thus shifting their focus from products to end-solutions as a means to enhance their competitive advantage. The loT brings servitisation to its extreme consequences; indeed, when every machine and everyday object is embedded with services and software, it becomes meaningless to imagine goods and services as separate entities. Smart devices have outnumbered human beings. They are allowing a number of actors that were excluded from traditional manufacturing to provide new and cheaper services in several fields, including smart home, smart cities, smart grids, and quantified self. The creation of loT-enabled services may ultimately benefit vulnerable stakeholders, including SMEs and entrepreneurs in developing and least developed countries, by contributing towards key sustainable goals such as decent work and economic growth, as well as industry, innovation, and infrastructure.

11. For Al and the loT to unleash their potential thus facilitating the achievement of the sustainability agenda, it is crucial that they be governed adequately by the law, and in particular by IP Law.

12. IP is the law that creates temporary monopolies on inventions, literary works, and other intellectual creations in order to incentivise innovation and creativity. The main examples of IP rights include copyright, patents, trade marks, designs, and trade secrets. For many companies, including SMEs, IP assets are more valuable than physical assets. According to Interbrand, Apple's trademarks 
are worth USD 215,000m; Amazon's branding value has jumped an outstanding $+56 \%$ last year. The key to Google's success is a trade secret on their search algorithm and on their data monetisation methods. IP laws are a vital element of any sustainability strategy, in that they can promote innovation and economic growth, while reducing inequalities and improving access to health. However, depending on how they are interpreted and on which stakeholders can exercise actual influence on the lawmaking process, IP laws can also run counter the sustainability goals. I will make a healthcare-related example in a minute.

13. IP can determine the success of Al and loT or it could doom them to failure. To understand whether Al and loT can be governed to contribute to achieving the sustainable development goals, we need to critically see if IP laws are fit for purpose. This means answering the fundamental question whether, in a world of Al and IoT, IP laws can still incentivise innovation and creativity while striking a balance between private and public interests, economic and non-economic ones.

14. I would like to make just two examples of how IP laws govern - or fail to govern - Al and the loT. I trust we can discuss other IP issues in these technologies during the Q\&A. Pharmaceutical patents and $\mathrm{Al}$ are the first case study.

15. One of the sustainable development goals is good health and this can be achieved only if those who need medicines can access them on fair terms. Patents are the main device that regulates access to medicines by granting temporary monopolies to pharmaceutical industries developing new drugs. Patents are not absolute rights in that they are temporary (usually 20 years) and are limited by exceptions (e.g. private and non-commercial use). Moreover, unlike trade secrets, applicants must disclose the way the invention works clearly and completely enough for it to be performed by a "person skilled in the art". This disclosure should lead to a race to innovate where competitors develop better versions of the invention to be launched on the market when the patent expires. However, many IP scholars have noted that the industry has abused the patent system through several practices that allow them absolute and virtually permanent monopolies on medicines. The thought goes to the 'evergreening' strategies to factually retain a perpetual monopoly at the expenses of generics' producers and patients more generally. They include data exclusivity, supplementary protection certificate, altering or reformulating the existing compound to obtain a new patent by utilising polymorphism, creating combinations, stereo-selective/chiral switches, etc. (more in Kumar \& Nanda 2017; Gurgula 2018). Thus, pharmaceutical patents enable pharmaceutical companies to keep the prices of vital medicines so high as to be unaffordable to those in need, especially in developing and least developed countries.

16. These practices, albeit open to criticism, may be regarded as lawful under most patent regimes. The main reason for this is that the requirements for patentability have been interpreted in an increasingly loose way. To obtain a medicinal patent, pharmaceutical companies must prove that their invention is new, requires an inventive step, is capable of industrial application, and that it does not fall within the so-called 'excluded subject matter'. These requirements are straightforward and easy to meet when applying for a pharmaceutical patent. The only slightly problematic requirement is the 'inventive step' - it can be useful to say a couple of words about it, also because it may be radically rethought in light of the widespread use of Al. Under Article 56 of the European Patent Convention, "[a]n invention shall be considered as involving an inventive step if, having regard to the state of the art, it is not obvious to a person skilled in the art."

17. The more knowledgeable and capable of ingenuity this hypothetical personal skilled in the art is, the harder it will be for the applicant to meet the 'inventive step' requirement, because it will be likely that such a person will consider the invention obvious and thus not patentable. As clarified by 
the European Patent Office (EPO)'s Guidelines, the 'person skilled in the art' is presumed to be a skilled practitioner in the relevant field of technology, who possesses average knowledge and ability and is aware of what was common general knowledge in the art at the relevant date (e.g. T 4/98; T 143/94; T 426/88). This 'person skilled in the art', however, is not expected to know everything. For example, the EPO Boards of Appeal held that a single publication (e.g. a patent document, but also the content of a technical journal) cannot normally be considered as common general knowledge (T 475/88). This person - the standpoint to assess inventive step - is not a highly skilled expert or a Nobel prize winner, nor are they some form of lowest common denominator (General Tire \& Rubber Co v Firestone Tyre \& Rubber Co Ltd). They do not have the skills to exercise inventive ingenuity or think laterally; in Jacob LJ's words, the person skilled in the art, if real, would be very boring - a nerd (Technip France SA's Patent).

18. If a notional person skilled in the art finds the invention non-obvious, it is likely that the applicant will be granted a patent. Since currently this person is seen as lacking ingenuity and equipped with limited knowledge, it follows that they will find the invention non-obvious and hence patentable with relative ease. This is where Al can play a role in rebalancing the patent system and make it fitter for the sustainability goals. Al increasingly powers innovative forms of data mining and other automated research tools. Scientists and researchers can enhance their own ingenuity and knowledge though a myriad of Al applications. Hence the question whether we should abandon the traditional idea of 'person skilled in the art' and assess the inventive step of future inventions from the viewpoint of the Al-enhanced researcher (see Samore 2013; Yanisky-Ravid \& Liu 2018). This new standard would make it harder to meet the inventive step requirement, which would at least partly counter the pharmaceutical companies' abuses of the patent system. Thus, Al may lead to a recalibration of the system towards an increased access to medicines.

19. Aware of time constraints, I will deal more briefly with how IP governs the other key technology we are talking about, i.e. the loT. As I touched upon before, one of the requirements for patentability is that the invention does not fall within the so-called excluded subject matter (Article 52 of the European Patent Convention). This means that there are public policy reasons not to allow patents on certain things, such as discoveries and scientific theories. Computer programs are the most controversial excluded subject matter. Applicants will not be granted a patent if the invention regards software 'as such' (Article 52(3)). The EPO interpreted this exclusion to mean that a computer program can be patented if it produces a 'further technical effect' when run on a computer (T 1173/97 and G 3/08). Computer programs will have a technical effect, for example, when they affect a process that is carried out outside the computer or make the computer run more efficiently or effectively (HTC $v$ Apple). The loT is likely to have an impact on the patent system in that the latter rests on the software-hardware dichotomy, that the loT disrupts, and because smart devices are increasingly used to control real-world processes and make traditional devices more effective. Thus, most loT software may be seen as producing a 'further technical effect' and hence be patentable. With the ubiquitous presence of the loT, we may factually overcome the software's exclusion from patentability. It should not come as a surprise, therefore, that loT patents and applications increase annually on average more than $40 \%$ compared to an average $6 \%$ annual increase across all other technologies (UKIPO 2014). Allowing generalised software patentability would not be positive, because it would likely lead to chilling effects and to the deployment of loT devices and systems that are proprietary and therefore go against the openness ethos of the loT. Indeed, the loT must be open and interoperable, otherwise it risks becoming the Internet of Silos.

20. We could look at other IP issues regarding AI and loT, but for the sake of brevity I will conclude now. The WTO and all of us can play an important role in achieving the UN sustainable development 
goals. Investments in Al and loT could go a long way, in that these technologies could lead to economic growth, innovation, good health, and new services. For this to happen, however, they must be adequately governed. This means, practically, that we need laws - and IP laws above all, given their role in incentivising creativity and innovation - that are fit for Al and loT. As shown above, Al could lead to unprecedented research developments with revolutionary impact on healthcare. They would do so not only by changing the way we carry out research - with Al-powered data mining and cancer-predicting deep learning models - but also by making us rethink certain IP laws. The reference is to the patent system that has hitherto been abused by pharmaceutical companies that have developed strategies to retain perpetual and absolute monopolies on medical inventions, thus preventing access to medicines, especially in developing and least developed countries. Al could change this. It could, indeed, change the standard currently applied to assess one of the key requirements for patentability, i.e. inventive step. We currently assess if an invention presupposes an inventive step and is hence patentable from the point of view of the 'person skilled in the art', a notional worker who lacks ingenuity and has limited knowledge. With Al becoming commonplace and increasingly creative, the new standard to be adopted may and should be the Alenhanced researcher. Such a person would be more likely to consider new inventions as obvious and this would counter the over-protection of pharmaceutical inventions. Finally, the loT is set to disrupt all the fields and all the laws that have been built on the good-product and hardware-software dichotomy. Patent laws are likely to be profoundly impacted - and may need a significant revision because their exclusion from patentability of software may be factually circumvented by the ubiquitous presence of software in any mundane device and at any step of the supply chain. To conclude, IP laws are likely to play a limited role in governing AI and the IoT. It seems more probable that these technologies will 'govern' current IP laws in the sense of leading to new interpretation and policies that will make them more 'sustainability-friendly'.

Thank you.

For references and more in-depth analyses see Guido Noto La Diega, 'Artificial Intelligence and Databases in the Age of Big Machine Data' (2019) 25 AIDA 2018 93; Guido Noto La Diega, 'Against the dehumanisation of decision-making. Algorithmic decisions at the crossroads of intellectual property, data protection, and freedom of information' (2018) 9(1) JIPITEC Journal of Intellectual Property, Information Technology and Electronic Commerce Law 3; Guido Noto La Diega, 'Software patents and the Internet of Things in Europe, the United States, and India' (2017) 39(3) European Intellectual Property Review 173; and Guido Noto La Diega, The Internet of Things and the Law (Routledge 2020). 